\title{
Survival Analysis to Determine the Length of the Incubation Period of Camellia Twig Blight Caused by Colletotrichum gloeosporioides
}

\author{
W. E. Copes, USDA-ARS Southern Horticultural Laboratory, Poplarville, MS 39475; and J. L. Thomson, USDA- \\ ARS Southern Regional Research Center, Baton Rouge, LA 70808
}

\begin{abstract}
Copes, W. E., and Thomson, J. L. 2008. Survival analysis to determine the length of the incubation period of Camellia twig blight caused by Colletotrichum gloeosporioides. Plant Dis. 92:1177-1182.

Camellia twig blight, caused by Colletotrichum gloeosporioides, is a disease common to several Camellia species in the southern United States. To determine the potential seasonal differences in incubation periods, stems of Camellia sasanqua 'Rosea' plants grown in pine bark under ambient conditions were wounded and inoculated monthly with $C$. gloeosporioides mycelium. The time until appearance of the first symptom of disease (incubation period length) was recorded for all stems. Stems that did not display a disease symptom by the last day of the observation period were recorded as censored observations. Survival analysis using Kaplan-Meier estimates, Cox proportional hazards, and extended Cox models was used to analyze the data. Incubation period length was regressed against stem diameter, monthly mean hours per day in a specified temperature range ( 15 to $30^{\circ} \mathrm{C}$ ), and a categorical season variable approximating the four host growth stages (winter dormancy, spring leaf and stem growth, summer stem hardening and bud set, fall cessation of leaf and stem growth and opening of flowers) at the time stems were inoculated. Stems of thicker diameter tended to have greater incubation period length, while higher monthly mean hours per day in the specified temperature range decreased incubation period length. In comparison to winter months, spring, summer, and fall months were all associated with significantly higher risks for disease symptom appearance. The median incubation period lengths for the spring, summer, fall, and winter months were 18, 23, 28, and 57 days, respectively.
\end{abstract}

Additional keywords: dieback, stem blight, stem canker

Camellia twig blight (CTB) is caused by Colletotrichum gloeosporioides (Penz.) Penz. \& Sacc. (teleomorph: Glomerella cingulata (Stoneman) Spauld. \& H. Schrenk). The disease is prevalent in the southern United States because many cultivars of the Camellia species C. japonica, $C$. reticulata, and $C$. sasanqua grown in this region are susceptible to infection by the pathogen $(6,7,10,14)$, and environmental conditions in this region are favorable for disease development $(3,10,21,29)$.

The methods currently followed to control CTB include the application of fungicides (thiophanate methyl, propiconazole) to protect against infection through fresh leaf scars in the spring and through wounds following the collection of propagation wood, the removal of blighted stems that could serve as a source of inoculum, the application of a low rate of a balanced

Corresponding author: W. E. Copes

E-mail: warren.copes@ars.usda.gov

Accepted for publication 8 April 2008.

doi:10.1094/PDIS-92-8-1177

This article is in the public domain and not copyrightable. It may be freely reprinted with customary crediting of the source. The American Phytopathological Society, 2008. fertilizer to avoid rapid growth associated with increased CTB susceptibility, and the collection of stems for vegetative propagation from nonsymptomatic plants $(3,5,8-$ 10,14,15,17,21). A few Camellia spp. cultivars have tolerance to $C$. gloeosporioides $(6,7)$; however, typical of many ornamental plant selections, consumers select Camellia spp. cultivars primarily based on horticultural traits and not strictly on disease tolerance ratings.

Some of the basic pathology information from which controls for CTB were developed has been based on a combination of field experiments and observations (3-5,10,15,17,22). However, the information does not completely explain disease development on camellia nor coincide with data about Colletotrichum diseases on other hosts $(2,27,29)$. With CTB, the primary infection period for $C$. gloeosporioides has been attributed to conidia infecting through leaf scars resulting from natural leaf senescence in May and June $(3,10)$. Camellias are broadleaf evergreens that shed older leaves during the spring. The naturally resulting wound is reported to be vulnerable to infection for several days. Stem blight of small diameter shoots can develop in as little as 7 days (10). While CTB symptoms commonly appear during the spring, they also appear during the summer and fall months. There are two possible explanations for the appearance of CTB symptoms over a protracted time period: (i) infection can occur over a longer period of time before, during, and/or after leaf scars are susceptible; and (ii) incubation periods associated with leaf scar infections are highly variable, giving rise to the appearance of symptoms over an extended period of time. Can et al.'s (10) observation that leaf wilting symptoms can take up to 3 months to develop partly supports the latter explanation. However, their observations included larger stems older than 2 years in age and thus may not apply to current or previous year's stems, which are smaller in diameter.

The incubation period has not been studied extensively for Colletotrichum spp. in woody tissue or even in herbaceous stems. The progression of disease symptoms caused by Colletotrichum species and/or histological studies of the infection process have been described for alfalfa stems (25), cassava stems (34), custard apple seedlings (31), northern jointvetch seedlings (32), pine seedlings (24), poplar stems (23), and strawberry petioles (11). While periodic assessments were performed, none of these studies distinctly measured the incubation period.

Disease control methods typically must be applied prior to infection. Hence, understanding primary and secondary inoculum production relevant to tissue susceptibility and the incubation period (time from infection to the first appearance of a symptom) is important for evaluating control methods based on disease intensity measurements. While comparable data do not exist for CTB, Colletotrichum species can produce conidia through most of the year from woody tissue in areas with mild to moderate winters $(16,19,35)$ and potentially produce ascospores in the southeastern United States (33). The incubation period associated with infection of woody stems may be variable. Can et al. (10) observed that the incubation period varied with temperature, by size and age of stems, by cultivar, and by other factors, although they provided no objective, quantitative measurements in support of those statements.

The purpose of this research was to develop a basic understanding of differences in the CTB incubation period through the annual cycle of the four seasons. We wished to determine if inoculation of ca- 
mellia plants with $C$. gloeosporioides in different months over the course of 2 years led to incubation periods of differing lengths.

\section{MATERIALS AND METHODS}

Plant culture. Two-year-old Camellia sasanqua 'Rosea' plants, grown in pine bark in 3.8-liter containers, were obtained in June 2003 and May 2004. C. sasanqua 'Rosea' was selected because it is known to be moderately susceptible to CTB. Plants were maintained on a black plastic polypropylene fabric and watered with an overhead center-pivot irrigation system. All plants were fertilized with $16 \mathrm{~g}$ of Osmocote Pro 19-5-8 (Scotts Co., Marysville, $\mathrm{OH})$ prior to acquisition. Plants acquired in 2003 and used in 2004 were fertilized a second time on 26 March 2004. Inoculated plants were kept $18 \mathrm{~m}$ apart and downwind from noninoculated plants.

Inoculation procedure. An isolate of $C$. gloeosporioides (CG02g) was recovered from blighted Camellia sasanqua 'Rosea' stems collected from a container-grown plant from a southern Mississippi nursery in May 2002. Agar blocks, $36 \mathrm{~mm}^{2}$, were removed from the leading edge of mycelium growth to produce multiple plates. Conidial spore suspensions of $1 \times 10^{5}$ conidia/ml 10\% (wt/vol) nonfat dry milk solution were stored on silica gel in $16 \times$ $125 \mathrm{~mm}$ test tubes with threaded caps at $5^{\circ} \mathrm{C}$ (13). The single isolate was used throughout the study to minimize variability. For each inoculation period, a few grains of infested silica gel were set on Difco potato dextrose agar (PDA) in 100$\mathrm{mm}$ plastic petri plates and grown at $21^{\circ} \mathrm{C}$ under $12 \mathrm{~h}$ diurnal light and dark for 3 to 4 days.

Twenty-two periods (individual sets of plants) were run from June 2003 to April 2005. A period was defined as a set of plants inoculated at a monthly interval. All plants of a period were inoculated in a single day toward the end of a month. For the purpose of labeling, periods hereafter are referenced by the month following inoculation, which reflected the early ambient conditions to which plants were exposed and the use of temperature as an explanatory variable (see Statistical analysis section). Two to six stems were woundinoculated per plant on three to five plants, totaling 10 to 17 inoculated stems per period. Stem diameter was measured with a metric caliper at the point of inoculation prior to inoculation. For the first six periods, stem selection consisted of those with a diameter range of 2.0 to $4.9 \mathrm{~mm}$ at the inoculation point. In the later 16 periods, starting with the seventh period, a narrower stem diameter range of 1.5 to 2.9 $\mathrm{mm}$ was used. Plants were wounded 2 to 7 $\mathrm{cm}$ from the terminal end of a stem by cutting off a leaf, typically the fourth to seventh from the apical end, at the base of its petiole with a sterile scalpel. Terminal branch ends are the youngest stem growth on the plant. A $3.6 \mathrm{~mm}^{2}$ piece of agar with the leading edge of young mycelium, where conidium production had not yet been initiated, was placed against the wound and sealed with Parafilm. Plants were kept at approximately 23 to $27^{\circ} \mathrm{C} / 15$ to $19^{\circ} \mathrm{C}$ day/night temperatures in a greenhouse for 3 days; thus the incubation period response was isolated from the infection process. Seventy-two hours later, the Parafilm and agar block were removed and plants were placed outside on the production pad. Plants were subsequently exposed to the natural range of fluctuating ambient temperatures that occur in the Gulf Coast climate concurrently with seasonal differences in host physiology.

To verify that neither wounds nor the inoculation technique resulted in unintentional infections, three stems per each of two plants were agar-inoculated. A 3.6 $\mathrm{mm}^{2}$ sterile block of PDA was placed on the wound and sealed with Parafilm for 3 days in the greenhouse. The agarinoculated plants were placed on the production pad, at least $18 \mathrm{~m}$ and upwind from the inoculated plants and at least 13 $\mathrm{m}$ from the plants that would be inoculated in later periods.

To provide a measure of the month-tomonth variance in isolate pathogenicity and/or in the rate of disease development due to the plant's seasonal change in physiology (active growth to dormancy), two upper-stems per plant were agarinoculated and two mid- to lower-stems per plant were pathogen-inoculated for two plants as previously described. The plants were maintained in the greenhouse and hand-watered as needed at the base of the trunk.

Disease assessment and weather data. Plants were monitored weekly for symptoms, typically on Monday, Wednesday, and Friday, throughout the study period. The initial appearance of symptoms was marked by at least one of the following conditions: leaves with chlorotic or reddish tissue, marginal necrosis, wilted leaves that had a dull green-gray color, or leaves that were completely necrotic. It should be noted that not all plants progressed through successively worsening symptoms of disease; hence the first sign of disease (whether it was mild or severe in appearance) indicated the end of the incubation period. Periods were terminated when all or most of the pathogen-inoculated stems had become completely blighted or no changes had occurred in the few remaining pathogen-inoculated stems for two or more weeks. This resulted in periods that were not uniform in length. Plants that were agar-inoculated at the start of a period and maintained on the production pad were checked at the same time. Plants that were agar- and pathogen-inoculated at the start of the period and maintained in the greenhouse were terminated separately from the plants maintained on the production pad, usually within 34 to 40 days after the inoculation date.

When a period was terminated, all inoculated stems were pruned several centimeters below the inoculation point and surface-sterilized for $1 \mathrm{~min}$ in $10 \%$ bleach. Using flame-sterilized scalpels, slices of the stem were removed at the margin of healthy-appearing and discolored wood below the inoculation point and 3 to $6 \mathrm{~cm}$ distal of the inoculation point, which typically was completely dead wood. Stem slices were plated on PDA and recovery of C. gloeosporioides and Glomerella cingulata recorded. For stems that had not become blighted, the extent of internally discolored wood above and below the inoculation point and percent internal discoloration around the circumference of the cambial region were recorded.

Because temperature likely played an important role in the length of the incubation period, it was continuously monitored for inclusion as an explanatory variable in the model. Daily temperature was recorded in 15-min intervals, using a HOBO H8 Pro Series temperature and relative humidity data logger (Onset, Pocasset, MA). The data logger was maintained in a radiation shield and positioned $33 \mathrm{~cm}$ above the production pad, beside the plants.

Statistical analysis. The time (in days) from inoculation until appearance of the first initial symptom(s) of disease was modeled using Cox proportional hazards and extended Cox models for survival analysis. The Kaplan-Meier method was used to produce estimates of the incubation curves and median incubation period lengths. Survival analysis represents the most appropriate statistical methods available to handle time-to-event data, especially when censoring or time-dependent covariates are involved $(1,18,28)$. While the Cox proportional hazards model can be used for data in which the hazard ratios remain constant over time, the extended Cox model (a modified version) should be used when the proportional hazards assumption is violated. The exact procedure for handling ties (assumed ties are the result of imprecise measuring because stems were not inspected daily) was used. The hazard regression model for timedependent covariates has the following form:

$$
h(t, \boldsymbol{x}, \boldsymbol{\beta})=h_{0}(t) \exp \left[\boldsymbol{x}^{\prime}(t) \boldsymbol{\beta}\right]
$$

where $t$ is time to event, $\boldsymbol{x}$ is a vector of covariates or explanatory variables, and $\boldsymbol{\beta}$ is a vector of unknown parameters to be estimated; $h_{0}(t)$ is a baseline hazard function that involves time but not the predictor variables; and $\exp \left[\boldsymbol{x}^{\prime}(t) \boldsymbol{\beta}\right]$ is a linear function of a set of predictor variables that accounts for time-dependence such as nonproportional hazards in the model.

Explanatory variables which were tested for inclusion in the models included a 
categorical period variable representing the 22 inoculation periods, a continuous temperature variable based upon the average hours per day within a specified temperature range (STR) of 15 to $30^{\circ} \mathrm{C}$ for the month following inoculation, a categorical season variable, stem diameter, and stem leaf number. Initially, a categorical period variable representing the inoculation periods was included in the model because it was part of the experimental design of the study. However, it quickly became clear that interpretation of this variable in the proportional hazards models would be difficult. Hence the STR variable was created to replace the period variable. Different methods for representing the temperature-based variable were used in an effort to account for the variability seen among the 22 inoculation periods. These measurements included mean hours per day within a specified temperature range for the week of, month of, and month after inoculation; and mean temperatures for the month and week after inoculation. The mean hours per day were calculated by summing the number of hours within a specified temperature range for the defined time interval (cumulative effect) and dividing this total by the number of days in the time interval (weighted effect). Various temperature ranges were used in the models (ranging from 13 to $30^{\circ} \mathrm{C}$ ) with the final range selection based upon Aike's information criteria for model fit and the $P$ values of the variable coefficients.

The categorical season variable was comprised of four classes, representative of different growth phases associated with the four seasons of the year, and based on a combination of observational notes and quantitative leaf-growth data taken from the plants. The winter season representing dormancy was composed of December, January, February, and March. The spring season representing leaf and stem growth was composed of April, May, and June. The summer season representing stem hardening and bud set was composed of July, August, and September. The fall season representing cessation of leaf and stem growth and opening of flowers was composed of October and November. The month of inoculation was used to classify the season category.

During the initial course of the experiment (July 2003 to December 2003; periods 1 to 6 ), it was noted that incubation period length appeared to be affected by stem diameter even though fairly uniform stems had been selected. Since stem diameter was not purposely included as a treatment factor in the experiment, stems were selected with an even more uniform diameter starting with February 2004 (period 7) and thereafter. However, we felt it prudent to include stem diameter as a covariate in the Cox regression models based upon the observations concerning a possible stem diameter effect in the first six periods.
Survival analysis relies upon the assumption of independence of the observations, a potential concern for this study since multiple stems from the same plants were included in the analysis. To ensure that correlation among stems of the same plants was not a problem, one-way analysis of variance (ANOVA) tests for incubation period length were performed sepa- rately for each of the 22 periods with plant representing the factor. If the betweenplant variance was significantly greater than the within-plant variance, this would lend evidence in support of significant correlation between stems of the same plant (e.g., stems from the same plant were behaving as individual groups instead of as one large group). Additionally, to test all

Table 1. Descriptive statistics of 22 inoculation periods of twig blight of Camellia sasanqua 'Rosea' inoculated with Colletotrichum gloeosporioides

\begin{tabular}{|c|c|c|c|c|c|c|}
\hline \multirow[b]{2}{*}{$\begin{array}{l}\text { Period by month } \\
\text { and year }\end{array}$} & \multicolumn{3}{|c|}{ Field plants } & \multicolumn{3}{|c|}{ Greenhouse plants } \\
\hline & $\begin{array}{l}\text { No. of } \\
\text { stems }\end{array}$ & $\begin{array}{c}\text { Censored }^{b} \\
\text { no. }(\%)\end{array}$ & $\begin{array}{c}\text { Median } \\
\text { incubation } \\
\text { (days) }\end{array}$ & $\begin{array}{l}\text { No. of } \\
\text { stems }\end{array}$ & $\begin{array}{c}\text { Censored } \\
\text { no. }(\%)\end{array}$ & $\begin{array}{c}\text { Median } \\
\text { incubation } \\
\text { (days) }\end{array}$ \\
\hline July 2003 & 10 & $1(10.0)$ & 24.0 & 2 & $0(0.0)$ & 22.5 \\
\hline August 2003 & 12 & $3(25.0)$ & 19.5 & 4 & $0(0.0)$ & 16.0 \\
\hline September 2003 & 12 & $1(8.3)$ & 15.5 & 4 & $2(50.0)$ & $19.8^{c}$ \\
\hline October 2003 & 12 & $2(16.7)$ & 43.0 & 4 & $1(25.0)$ & 50.0 \\
\hline November 2003 & 12 & $0(0.0)$ & 28.0 & 4 & $0(0.0)$ & 24.5 \\
\hline December 2003 & 17 & $7(41.2)$ & 60.0 & 4 & $0(0.0)$ & 45.5 \\
\hline February 2004 & 12 & $1(8.3)$ & 76.0 & 4 & $0(0.0)$ & 23.0 \\
\hline March 2004 & 13 & $2(15.4)$ & 39.0 & 4 & $0(0.0)$ & 26.0 \\
\hline April 2004 & 12 & $1(8.3)$ & 27.5 & 4 & $0(0.0)$ & 18.0 \\
\hline May 2004 & 14 & $0(0.0)$ & 18.0 & 4 & $0(0.0)$ & 16.5 \\
\hline June 2004 & 14 & $0(0.0)$ & 13.0 & 4 & $0(0.0)$ & 15.0 \\
\hline July 2004 & 12 & $4(33.3)$ & 34.0 & 4 & $0(0.0)$ & 22.5 \\
\hline August 2004 & 12 & $0(0.0)$ & 22.5 & 4 & $0(0.0)$ & 18.5 \\
\hline September 2004 & 12 & $1(8.3)$ & 26.5 & 4 & $0(0.0)$ & 16.0 \\
\hline October 2004 & 12 & $0(0.0)$ & 26.0 & 4 & $0(0.0)$ & 13.0 \\
\hline November 2004 & 12 & $1(8.3)$ & 26.5 & 4 & $0(0.0)$ & 28.0 \\
\hline December 2004 & 12 & $0(0.0)$ & 72.0 & 4 & $0(0.0)$ & 12.5 \\
\hline January 2005 & 12 & $0(0.0)$ & 34.5 & 4 & $0(0.0)$ & 22.0 \\
\hline February 2005 & 12 & $0(0.0)$ & 64.5 & 4 & $0(0.0)$ & $14.0^{\mathrm{c}}$ \\
\hline March 2005 & 12 & $1(8.3)$ & 47.0 & 3 & $0(0.0)$ & $17.0^{\mathrm{c}}$ \\
\hline April 2005 & 12 & $0(0.0)$ & 24.0 & 4 & $0(0.0)$ & 6.0 \\
\hline May 2005 & 14 & $0(0.0)$ & 13.0 & 4 & $0(0.0)$ & 10.0 \\
\hline Total & 274 & $25(9.1)$ & & 85 & $3(3.5)$ & \\
\hline
\end{tabular}

a This is the month following inoculation for the respective period.

${ }^{\mathrm{b}}$ Number and (percent) stems that did not express a disease symptom by the last day of the observation period.

${ }^{\mathrm{c}}$ Mean value reported since no median value was obtainable (noncensored plants had disease symptom appearance occurring on same day).

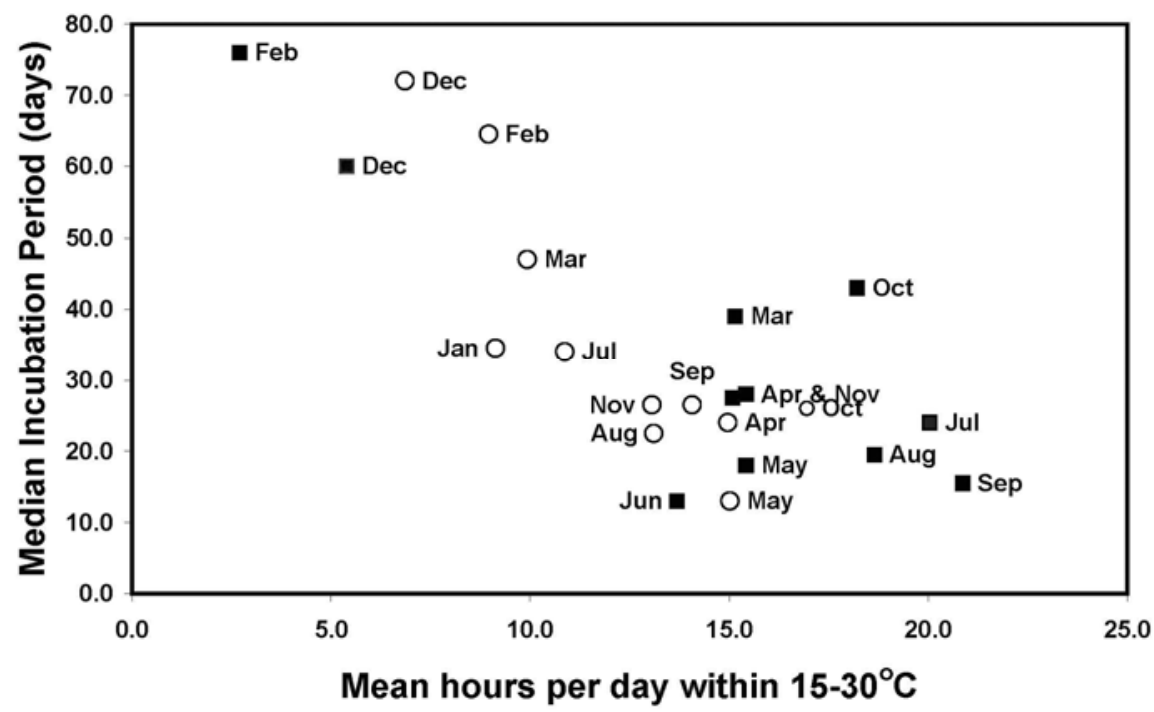

Fig. 1. Mean hours/day temperature was between 15 and $30^{\circ} \mathrm{C}$ across the duration of a period's full month following inoculation, July 2003 to June 2004 (-) and July 2004 to May 2005 (०), versus median incubation period in days for Camellia sasanqua 'Rosea' stems inoculated with Colletotrichum gloeosporioides. Abbreviated month labels are shown mostly to the right of the corresponding symbol except for January 2005, November 2004, August 2004, and June 2004, whose labels are to the left, and September 2004, whose label is immediately above the corresponding symbol. 
22 periods together, a random effects ANOVA using a hierarchical structure for plants nested within a period was also performed for incubation period length. Results were considered significant at the nominal level of 0.05 . All statistical analyses were performed using SAS version 9.1 and SPSS version 14.0.

\section{RESULTS}

Twenty-two different inoculation periods occurred over the course of 23 months, spanning three calendar years (July 2003 to May 2005). For year one, inoculation periods corresponded to all calendar months except for January. For year two, inoculation periods corresponded to all calendar months except for June. A total of
274 inoculated stems comprised the field data, while 85 stems comprised the greenhouse data. The percentage of censored stems (those that did not display a disease symptom by the last day of the observation period) ranged from 0 to $41.2 \%$ (December 2003) for the field plants and from 0 to $50 \%$ (September 2003) for the greenhouse plants (Table 1). Median incubation length ranged from 13 (June 2004 and May 2005) to 76 days (February 2004) for the field plants and from 6 (April 2005) to 50 days (October 2003) for the greenhouse plants (Table 1). The range of median survival times for the greenhouse data was larger than expected for plants not exposed to natural weather conditions. However, when included as a covariate in the field

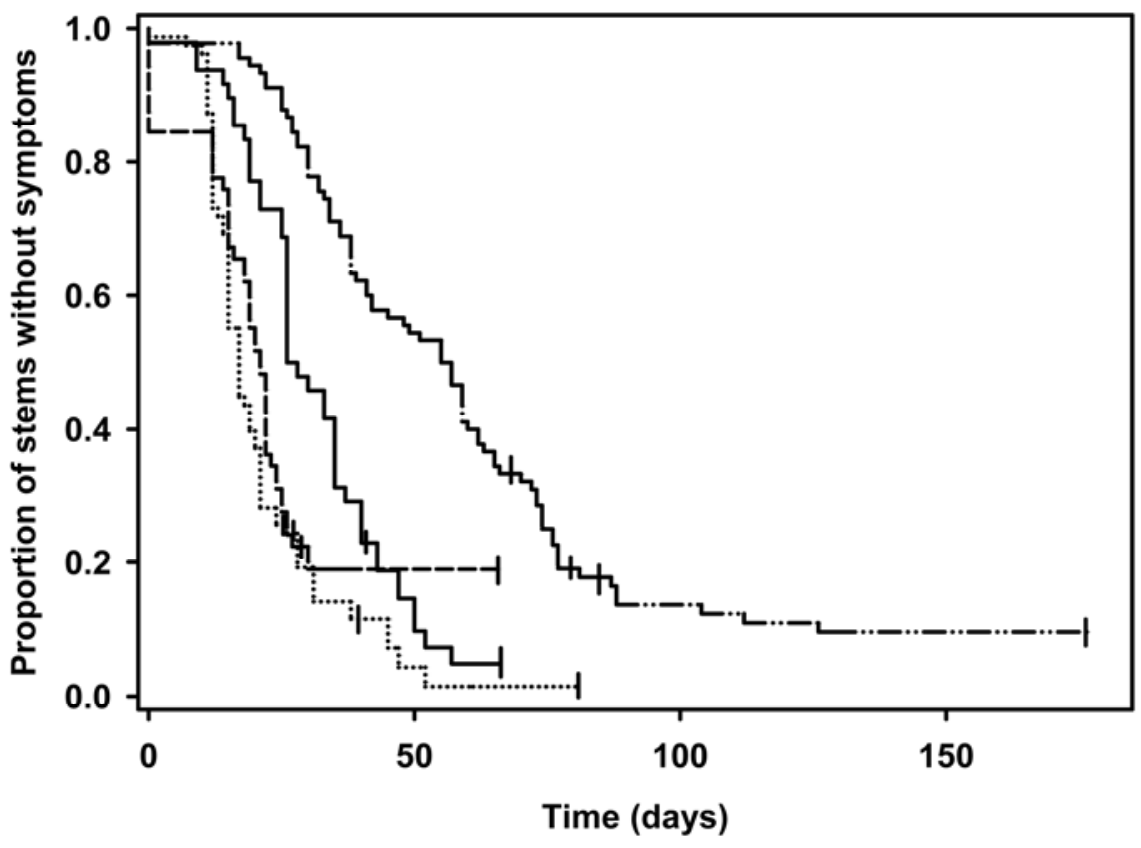

Fig. 2. Kaplan-Meier survival curves for the seasonal incubation periods of twig blight caused by Colletotrichum gloeosporioides on Camellia sasanqua 'Rosea' stems. Seasons are spring (line of all short dashes), summer (line of all long dashes), fall (solid line), and winter (line of short and long dashes). A plus symbol (+) indicates a censored stem (one that did not express a disease symptom by the last day of the observation period).

Table 2. Descriptive statistics and median ratios for the season categories for the incubation period length of twig blight of Camellia sasanqua 'Rosea' inoculated with Colletotrichum gloeosporioides

\begin{tabular}{lccccc}
\hline Season & $\begin{array}{c}\text { No. of } \\
\text { stems }\end{array}$ & $\begin{array}{c}\text { Censored }^{\mathbf{a}} \\
\text { no. }(\boldsymbol{\%})\end{array}$ & $\begin{array}{c}\text { Median incubation } \\
\text { (days) }\end{array}$ & Std error $^{\mathbf{b}}$ & $\mathbf{9 5 \%}_{\mathbf{C}} \mathbf{I}^{\mathbf{c}}$ \\
\hline Winter & 90 & $11(12.2)$ & 57.0 & 4.01 & $49.1,64.9$ \\
Spring & 78 & $2(2.6)$ & 18.0 & 0.55 & $16.9,19.1$ \\
Summer & 58 & $9(15.5)$ & 23.0 & 1.04 & $21.0,25.0$ \\
Fall & 48 & $3(6.3)$ & 28.0 & 2.40 & $23.3,32.7$ \\
Comparison & & Median ratio & & & \\
Winter/spring & & 3.2 & & & \\
Winter/summer & 2.5 & & & \\
Winter/fall & 2.0 & & & \\
Fall/spring & 1.6 & & & \\
Fall/summer & 1.2 & & & \\
Summer/spring & & 1.3 & & & \\
\hline
\end{tabular}

a Number and (percent) stems that did not express a disease symptom by the last day of the observation period.

${ }^{\mathrm{b}}$ Standard error of median incubation.

c $95 \%$ confidence interval of median incubation.

data model, median survival time for the greenhouse plants was not a significant factor in the model. Figure 1 illustrates the strong, negative relationship between median incubation period length and monthly mean hours within the STR for the month following inoculation.

Despite the lack of external symptom expression, all censored stems had internal stem necrosis associated with the point of inoculation, and C. gloeosporioides was recovered on PDA from the margin of healthy and necrotic internal wood (data not shown). Stems that were agarinoculated (noninoculated) monthly and placed in outdoor ambient conditions or in the greenhouse did not develop external or internal disease symptoms.

Independence assumption. Results from the individual one-way ANOVA tests for differences in the appearance of disease symptoms among plants revealed statistical significance in only two of the 22 periods: March and May of $2004(P=0.0083$ and 0.0321 , respectively). In addition, results from the hierarchical ANOVA revealed that while $54.1 \%$ of the variability was coming from the period variable for incubation length, essentially no variability $(0 \%)$ was coming from the plant variable. The ANOVA results suggested that observations from different twigs on the same plant can be considered independent for incubation period length.

Kaplan-Meier estimates of seasonal survival curves and median ratios (field data). It is evident that winter incubation period lengths were much greater than incubation period lengths of the other three seasons (Fig. 2). Additionally, it appeared that fall incubation period lengths were greater than both the spring and summer lengths for approximately the first 50 days, after which all three curves were similar in shape. The spring and summer incubation curves were similar in appearance throughout their incubation period lengths.

The median incubation period lengths for the winter, spring, summer, and fall months were $57,18,23$, and 28 days, respectively (Table 2). To estimate the magnitude of benefit to an experimental unit by providing a measure of rate, median ratios were also computed (30). Based on median ratios, infected stems exposed to temperatures during the spring, summer, and fall would develop symptoms at a 3.2, 2.5, and 2.0 times faster rate, respectively (Table 2), than infected stems exposed to temperatures during the winter months.

Cox extended model (field data). The overall best fit for the field data was provided by a model that included stem diameter, a continuous temperature variable representing monthly mean hours/day within a STR for the month following inoculation, a categorical (dummy) variable representing season, and interaction terms for season and time to account for 
the nonproportionality present in the season variables. The STR was defined as temperatures ranging from 15 to $30^{\circ} \mathrm{C}$. Time is the number of days from inoculation to expression of an initial symptom. The fit of the data, including the selection of model variables and the STR temperature range, was based upon Aike's information criteria and $P$ values of the variable coefficients (or hazard ratios).

The interpretation of a multinomial categorical variable is highly dependent on the reference category. We used the winter season as the reference category because it was representative of stems with the longest incubation periods. Stem diameter had an estimated hazard ratio of 0.466 indicating a protective effect on disease symptom appearance (Table 3). This result indicates that for every $1-\mathrm{mm}$ increase in stem diameter there is a $53 \%[(0.466-1) \times$ $100 \%$ ] decrease in risk of symptom appearance. Monthly mean hours/day in the STR for the month following inoculation had an estimated hazard ratio of 1.073 indicating a negative effect on disease symptom appearance (Table 3). Hence, every $1-h$ increase in the mean/hours in the STR resulted in a $7 \%$ increase in risk of symptom appearance.

The longest incubation periods occurred during the winter season, the months (December to March) when plants are dormant to coming out of dormancy. Using the winter season as the reference category, the fall, spring, and summer seasons were all significantly different from winter, as can be evidenced by their significant hazard ratios. Stems infected during the spring, summer, and fall had hazard ratios of 27.0, 24.1, and 2.9, respectively (Table 3). This means that infected stems exposed to spring, summer, and fall temperatures had approximately 27, 24, and 3 times the chance of manifesting a disease symptom, respectively, than did one exposed to winter temperatures.

Cox proportional hazards model (greenhouse data). The overall best fit for the greenhouse data was provided by a model that included only stem diameter as an explanatory variable. Neither the continuous temperature variable representing monthly mean hours/day within the STR nor the categorical season variable was significant in the model, as would be expected since these plants were not exposed to seasonal temperature variances. Stem diameter had an estimated hazard ratio of 0.442 , indicating a protective effect on disease symptom appearance (Table 3). This result indicates that for every $1-\mathrm{mm}$ increase in stem diameter, there is a $56 \%$ decrease in risk of symptom appearance. This estimated decrease in risk is very close to that observed with the field data $(53 \%)$, indicating that the effect is fairly robust in the presence of monthly temperature variances and seasonal effects.

\section{DISCUSSION}

The length of an incubation period differed based on the month a stem was inoculated with C. gloeosporioides. It is quite evident that inoculation in the late fall and winter months results in longer incubation periods for infected stems than does inoculation in the spring and summer months. Based upon the hazard ratios, there is an approximately 3- to 27-fold increase in risk of disease symptom appearance for fall to spring exposure, respectively, compared to winter. The hazard ratios for both the spring and summer seasons should be interpreted cautiously, since their interactions with time were significant, indicating that their hazard functions were not proportional over time. Hence, the greatest difference in risk of symptom appearance between the spring and summer seasons versus the winter season is at the beginning of the stem's exposure to seasonal temperatures, and this difference decreases over time (based on hazard ratios less than one). Complementing the hazard ratios, the median ratios indicate that winter exposure results in an approximately 2 to 3 times longer incubation period length than does exposure in the other three seasons.

Although infection was not a natural event in the study, results indicated that symptoms which develop in May to June could potentially be a result of infections that occurred from February to May, when the median incubation periods ranged from being relatively long to short. The potential for longer incubation periods during winter months brings into question the possibility of infections from ascospores or conidia during late winter that result in symptoms that appear in late spring, thus overlapping the appearance of symptoms that result from infections by conidia through fresh leaf scars in spring. Periods of warm temperatures, favorable for spore production, occur during the winter months in the Gulf Coast region. In both temperate and tropi- cal climates, conidia of $C$. gloeosporioides have been captured from February to November from blighted twigs of other crops $(16,35)$. No one has reported on the development of G. cingulata on camellia in the southern United States, nor has it been confirmed with strawberry anthracnose in Florida, although it is suspected to be present (33). We recovered perithecia of $G$. cingulata several times in vitro (data not shown). This shows that an isolate from camellia in this region can produce perithecia but does not verify development of perithecia under ambient conditions. Confirmation of whether the teleomorphic state is produced in nature, when ascospores would be released, and whether conidia are likely produced during winter months could influence timing of earlyseason fungicide applications. This knowledge would also impact the selection of cultural practices that increase wounds during that time, such as selective pruning.

A significant hazard ratio was associated with the mean hours per day within the STR for the month following inoculation, and indicates an increased likelihood for blight symptoms to develop for every additional hour in the 15 to $30^{\circ} \mathrm{C}$ range. Although temperature contributed as an explanatory variable for differences in incubation period length, additional understanding of the influence of temperature could be derived from modeling the temporal response pattern of CTB development. Temporal modeling of diseases caused by Colletotrichum spp. on other crops showed the maximum rate of disease development occurring at several different specific temperatures, but all within the 15 to $30^{\circ} \mathrm{C}$ range $(12,20,26)$. The influence from seasonal differences in host physiology versus temperature on incubation period length was not clearly identified in our data, especially since season was not a significant factor in the model for plants grown in the greenhouse where temperature was regulated.

Table 3. Results of Cox models for the incubation period length of twig blight of Camellia sasanqua 'Rosea' inoculated with Colletotrichum gloeosporioides

\begin{tabular}{|c|c|c|c|c|}
\hline Explanatory variable ${ }^{a}$ & Hazard ratio & Std error ${ }^{b}$ & $95 \% \mathbf{C I}^{\mathrm{c}}$ & $P$ value \\
\hline \multicolumn{5}{|l|}{ Field plants ${ }^{\mathrm{d}}$} \\
\hline Diameter & 0.466 & 0.1515 & $0.346,0.627$ & $<0.0001$ \\
\hline Monthly mean hours/day in $\mathrm{STR}^{\mathrm{e}}$ & 1.073 & 0.0188 & $1.034,1.113$ & 0.0002 \\
\hline Summer & 24.090 & 0.5573 & $8.081,71.814$ & $<0.0001$ \\
\hline Spring & 26.960 & 0.4787 & $10.550,68.897$ & $<0.0001$ \\
\hline Fall & 2.895 & 0.2494 & $1.776,4.720$ & $<0.0001$ \\
\hline Summer $\times$ time $^{f}$ & 0.937 & 0.0184 & $0.904,0.972$ & 0.0004 \\
\hline Spring $\times$ time $^{\mathrm{f}}$ & 0.944 & 0.0149 & $0.917,0.972$ & 0.0001 \\
\hline \multicolumn{5}{|l|}{ Greenhouse plants } \\
\hline Diameter & 0.442 & 0.2869 & $0.252,0.775$ & 0.0044 \\
\hline
\end{tabular}

${ }^{a}$ Cox extended model used for field plants; Cox proportional hazards model used for greenhouse plants.

b Standard error of model coefficient.

c $95 \%$ confidence interval for hazard ratio.

${ }^{\mathrm{d}}$ Winter is reference category.

${ }^{\mathrm{e}}$ Postinoculation month mean hours/day temperature is in a specified temperature range (STR) of 15 to $30^{\circ} \mathrm{C}$ for 22 periods (inoculation months).

${ }^{\mathrm{f}}$ Interaction with time (accounts for the nonproportionality present in the season variables). 
Stem diameter was also a significant factor in the model and indicated a decreased risk of disease symptoms developing with each $1-\mathrm{mm}$ increase in stem diameter. Can et al. (10) also observed that incubation periods varied by size and age of stems. Anecdotal comments from camellia enthusiasts agree with Can's observations. Surprisingly, the stem diameter range of 1.5 to $4.9 \mathrm{~mm}$ resulted in a significant hazard ratio, although we attempted to standardize stem diameter. It would be expected that a larger hazard ratio for stem diameter would result if stems up to $40 \mathrm{~mm}$ in diameter were included. Camellia is a slow growing plant, and the range of stem diameters used in this study is representative of newly developing to 2-year-old stems. Hence, our study results are applicable to young stems, which typically are most susceptible to twig blight. While C. gloeosporioides does infect and blight small-diameter stems more frequently than large-diameter stems, smaller stems often branch off of larger stems. The larger stems often become infected due to blight of smaller branches. Cankers can develop on the larger stems where infection of a smaller branch occurred. Furthermore, the entire distal end of a larger stem can develop blight in a manner similar to that of smaller stems.

We demonstrated seasonal differences in incubation period lengths while accounting for stem diameter and the number of hours temperature was between 15 and $30^{\circ} \mathrm{C}$. However, the incubation period of CTB is only one component of disease development. Knowledge concerning incubation periods needs to be combined with understanding of seasonal inoculum production, inoculum sources (blighted stems, cankers, leaf spots), spore release patterns, conditions that favor infection, and disease progression to provide a more comprehensive understanding of CTB.

\section{ACKNOWLEDGMENTS}

Lavonne Stringer, biological science technician, was involved with inoculating plants, maintaining dataloggers, measuring stem diameter and extent of necrosis, and recovering and identifying the pathogen.

\section{LITERATURE CITED}

1. Allison, P. D. 1995. Survival analysis using SAS, a practical guide. SAS Institute, Cary,
NC.

2. Bailey, J. A., and Jeger, M. J. 1992. Colletotrichum biology, pathology and control. CAB International, Wallingford, England.

3. Baxter, L. W. 1974. Studies on twig blight, canker, and dieback of camellias. Am. Camellia Yearb. 1974:63-75.

4. Baxter, L. W., Jr., Can, N. H., and Fagan, S. C. 1978. Dieback of camellia - contagious or non-contagious. Am. Camellia Yearb. 1978:9195.

5. Baxter, L. W., Jr., Epps, W. M., and Fagan, S. G. 1980. A thirteen point program for the control of contagious Camellia dieback caused by the fungus Glomerella cingulata. Camellia J. $35: 22$.

6. Baxter, L. W., Jr., and Fagan, S. G. 1974. A comparison of the relative susceptibility of seedlings of Camellia japonica and C. sasanqua to dieback and canker caused by a strain of Glomerella cingulata pathogenic to camellias. Plant Dis. Rep. 58:139-141.

7. Baxter, L. W., Jr., Fagan, S. G., and Owen, M. G. 1982. Responses of selected Camellia reticulata cultivars to Glomerella cingulata, cause of contagious Camellia dieback and canker. Plant Dis. 66:1022-1024.

8. Baxter, L. W., Jr., Sprott, A. M., Segars, B., and Fagan, S. G. 1987. Black root rot and stem blight of camellia. Camellia J. 42:4-5.

9. Bertus, A. L. 1974. Fungicidal control of Camellia dieback J. Hortic. Sci. 49:167-169.

10. Can, N. H., Baxter, L. W., Jr., and Fagan, S. G. 1978. The status of our knowledge in 1978 of twig blight, canker and dieback of camellias caused by a strain of Glomerella cinuglata. Am. Camellia Yearb. 1978:75-91.

11. Curry, K. J., Abril, M., Avant, J. B., and Smith, B. J. 2002. Strawberry anthracnose: Histopathology of Colletotrichum acutatum and $C$. fragariae. Phytopathology 92:1055-1063.

12. Dannebeger, T. K., Vargas, J. M., Jr., and Jones, A. L. 1984. A model for weather-based forecasting of anthracnose on annual bluegrass. Phytopathology 74:448-451.

13. Dhingra, O. D., and Sinclair, J. B. 1995. Basic Plant Pathology Methods. 2nd ed. Lewis Publishers, Boca Raton, FL.

14. Dickens, J. S. W., and Cook, R. T. A. 1989. Glomerella cingulata on camellia. Plant Pathol. 38:75-85.

15. Dunlap, A. A. 1950. Control of anthracnose canker of camellia. Phytopathology 40:7.

16. Fitzell, R. D., and Peak, C. M. 1984. The epidemiology of anthracnose disease of mango: Inoculum sources, spore production and dispersal. Ann. Appl. Biol. 104:53-59.

17. Gill, D. L. 1957. Effects of some fungicides, fertilizers, insecticides, and pruning on $\mathrm{Ca}$ mellia dieback. Am. Camellia Yearb. 1957:53-61.

18. Hosmer, D., and Lemeshow, S. 1999. Applied Survival Analysis: Regression Modeling of Time to Event Data. John Wiley \& Sons, New York.

19. Howard, C. M., Mass, J. L., Chandler, C. K., and Albregts, E. E. 1992. Anthracnose of strawberry caused by the Colletotrichum complex in Florida. Plant Dis. 76:976-981

20. Irwin, J. A. G., Cameron, D. F., and Ratcliff, D. 1984. Influence of environmental factors on the development of the anthracnose diseases of Stylosanthes spp. Aust. J. Agric. Res. 35:473478.

21. Jeffers, S. N., and Baxter, L. W., Jr. 2001. Camellia diseases. Pages 100-107 in: Diseases of Woody Ornamentals and Trees in Nurseries. R. K. Jones and D. M. Benson, eds. American Phytopathological Society, St. Paul, MN.

22. Katz, S. J. 1948. Dieback. Am. Camellia Yearb. 1948:120-123.

23. Marks, G. C., Berbee, J. G., and Riker, A. J. 1965. Colletotrichum shoot blight of poplars For. Sci. 11:204-215.

24. Nair, J., and Corbin, J. B. 1981. Histopathology of Pinus radiata seedlings infected by Colletotrichum acutatum f. sp. pinea. Phytopathology 71:777-783.

25. Porto, M. D. M., Grau, C. R., de Zoeten, G. A., and Gaard, G. 1988. Histopathology of Colletotrichum trifolii on alfalfa. Phytopathology 78:345-349.

26. Pria, M. dalla, Amorium, L., and BergaminFilho, A. 2003. Quantification of monocyclic components of the common bean anthracnose. Fitopatol.-Bras. 28:401-407.

27. Prusky, D., Freeman, S., and Dickman, M B., eds. 2000. Colletotrichum. Host specificity, pathology, and host-pathogen interaction. American Phytopathological Society, St. Paul, MN.

28. Scherm, H., and Ojiambo, P. S. 2004 Applications of survival analysis in botanical epidemiology. Phytopathology 94:10221026.

29. Sinclair, W. A., Lyons, H. H., and Johnson, W. T. 1987. Diseases of Trees and Shrubs. Comstock Publ. Assoc., Ithaca, NY.

30. Spruance, S. L., Reid, J. E., Grace, M., and Samore, M. 2004. Hazard ratio in clinical trials. Antimicrobial Agents Chemotherapy 48(8):2787-2792.

31. Subiros, J., Flores, E., and Vargas, E. 1987. Study of anthracnose on Annona muricata L. II. Effect on stem morphology. Turrialba 37:287-294.

32. TeBeest, D. O., Templeton, G. E., and Smith, R. J., Jr. 1978. Histopathology of Colletotrichum gloeosporioides $\mathrm{f}$. sp. aeschynomene on northern jointvetch. Phytopathology 68:1271-1275.

33. Urena-Padilla, A. R., MacKenzie, S. J., Bowen, B. W., and Legard, D. E. 2002. Etiology and population genetics of Colletotrichum spp. causing crown and fruit rot of strawberry. Phytopathology 92:1245-1252.

34. van der Bruggen, P., and Maraite, H. 1987. Histopathology of cassava anthracnose disease caused by Colletotrichum gloeosporioides f.sp. manihotis. Parasitica 43:3-21.

35. Waller, J. M. 1972. Water-borne spore dispersal in coffee berry and its relation to control. Ann. Appl. Biol. 71:1-18. 